\title{
Pathogenesis of HIV Opportunistic Infection
}

National Cancer Institute

\section{Source}

National Cancer Institute. Pathogenesis of HIV Opportunistic Infection. NCI Thesaurus.

Code $\mathrm{C18925.}$

Induction or development of microbe-induced disease(s) in an immunocompromised HIV infected individual. 